\title{
ANALISIS FINANSIAL EKOWISATA HUTAN MANGROVE DI SEBUBUS KECAMATAN PALOH
}

\author{
Nur Istiqamah*, Ani Muani**, Eva Dolorosa** \\ *Alumni Magister Manajemen Agribisnis Fakultas Pertanian \\ Universitas Tanjungpura Pontianak \\ ** Staf Pengajar Fakultas Pertanian Universitas Tanjungpura Pontianak
}

\begin{abstract}
Ecotourism is one of the tourism support conservation effort. This tourism is also give a good appreciation to its environment, culture, history and local community participation. The ecotourism development in Sebubus mangrove area is initiated as an effort for tourism development that can support the conservation of mangrove forest that could potentially raise incomes and welfare support for local people.Location of this research at Sebubus Paloh. Data used in this research is primary data. Data analysis was using financial analysis with indicator : Net Present Value, Internal Rate of Return, Net Benefit Cost Ratio, Payback Period, Sensitivities analysis. The result of this study show that : ecotourism mangrove forest is feasible by considering NPV = Rp. 4.188.742, IRR = $21,68 \%$ dan Net $B / C=3,5$, payback period is 11 months. Sensitivity analysis with $10 \%$ benefits reduction scenarios is feasible.
\end{abstract}

Keywords :ecotourism, financial analysis, mangrove forest, Paloh

\section{PENDAHULUAN}

Fenomena yang terjadi di masyarakat saat ini baik nasional maupun internasional bahwa kekayaan yang hampir seluruhnya berada di kawasan hutan mangrove, kini menghadapi ancaman dan tekanan yang semakin besar. Pengelolaan sumberdaya alam hutan mangrove harus diusahakan agar memberikan manfaat yang sebesar-besarnya untuk memenuhi kebutuhan dan kepentingan rakyat baik materiil maupun spiritual dengan cara tidak merusak tata lingkungan hidup manusia (Brown, 2006). Untuk mengurangi tekanan kerusakan hutan mangrove tersebut dapat dilakukan suatu kegiatan yang berdampak positif terhadap kesejahteraan masyarakat sekitar dan tetap menjaga fungsi lestari hutan mangrove tersebut maka kegiatan investasi ekowisata ini memiliki kemampuan finansial, kawasan konservasi merupakan modal yang secara tidak langsung dapat menyediakan lapangan pekerjaan bagi masyarakat sekitar serta untuk meningkatkan kepedulian dan pemahaman masyarakat mengenai pentingnya menjaga kelestarian ekosistem hutan mangrove.

Potensi hutan mangrove di Kecamatan Paloh dominan hanya terdapat di Desa Sebubus, dengan pembagian potensi aktual pada muara Sungai Paloh 660 ha dan hulu Sungai Bemban Paloh 6.430 ha (Bappeda,2007). Selama ini masyarakat Desa Sebubus memanfaatkan hutan mangrove untuk kehidupan sehari-hari seperti untuk kayu bakar, tambak udang / ikan, budidaya siput, dan diambil daunnya untuk dijadikan atap rumbia. $\mathrm{Hal}$ inilah yang mendasari penulis ingin mengembangkan konsep ekowisata pesisir di Kecamatan Paloh, melihat ancaman tingkat kerusakan ekosistem di pesisir Kecamatan Paloh terjadi karena kurang sadarnya masyarakat pesisir (petani dan nelayan) untuk memanfaatkan potensi yang ada secara berkelanjutan.

Melihat potensi, ancaman dan prospek untuk pemberdayaan masyarakat tersebut penting untuk dilakukan penelitian tentang analisis kelayakan finansial pengembangan ekowisata hutan mangrove di Desa Sebubus. Analisis yang amati dari aspek finansial ini pada prinsipnya adalah memadukan konsep biaya, mafaat, kelayakan usaha dan konsep ekologi dalam usaha ekowisata. 
Berdasarkan latar belakang di atas yang menjadi permasalahan dalam penelitian ini adalah apakah ekosistem hutan mangrove di Sebubus layak untuk diusahakan sebagai kawasan ekowisata?

\section{METODE}

Penelitian dilakukan di Desa Sebubus Kecamatan Paloh Kabupaten Sambas. Dipilih secara sengaja dengan dasar pertimbangan bahwa daerah ini merupakan salah satu daerah yang mempunyai kawasan hutan mangrove cukup luas dibandingkan dengan wilayah lain di Kecamatan Paloh.

Sumber data yang akan digunakan meliputi data primer dan data sekunder. Data yang dikumpulkan mencakupdata primer, diperoleh melalui wawancara dengan kepala keluarga (petani dan nelayan) yang berhubungan langsung dengan ekosistem mangrove, aparat Desa, pemuka masyarakat, serta sumber-sumber yang berhubungan dengan penyusunan penelitian ini. Data sekunder dihimpun dari berbagai literatur dan sumber data lain dari instansi - instansi yang berkompeten dengan fokus kajian.

Metode analisis yang digunakan adalah analisis finansial dengan kriteria investasi yaitu NPV, Net Benefit cost Ratio, IRR, Payback Period, dan analisis sensitivitas.

1. Net Present Value (NPV)

Kriteria kelayakan suatu proyek adalah jika NPV > 0, dengan menggunakan rumus sebagai berikut :

$$
\begin{aligned}
\mathrm{N} & =\sum_{i=1}^{n} \frac{B t-C t}{(1+i)^{t}} \\
& =\sum(B t-C t)(D F)
\end{aligned}
$$

\section{Dimana :}

$\mathrm{Bt}$ : Manfaat proyek pada tahun $\mathrm{t}$

$\mathrm{Ct}$ : Biaya proyek pada tahun $\mathrm{t}$

i : Tingkat suku bunga (required rate of return)

$\mathrm{n}$ : Umur ekonomis proyek.

Kriteria:

NPV $>0$ (nol) $\rightarrow$ usaha/proyek layak (feasible) untuk dilaksanakan

$\mathrm{NPV}<0(\mathrm{nol}) \rightarrow$ usaha/proyek tidak layak (feasible) untuk dilaksanakan

$\mathrm{NPV}=0(\mathrm{nol}) \rightarrow$ usaha/proyek berada dalam keadaan BEP dimana TR=TC dalam bentuk present value (Gray, 1993)

2. Net Benefit Cost Ratio (Net B/C)

Pada Net Benefitt Cost Ratio (Net B/C) kriteria kelayakannya jika:

Net $B / C>1$ (satu) berarti proyek (usaha) layak dikerjakan

Net $\mathrm{B} / \mathrm{C}<1$ (satu) berarti proyek tidak layak dikerjakan

Net $B / C=1$ (satu) berarti cash in flows = cash out flows $(B E P)$ atau TR=TC

Dengan rumus sebagi berikut :

$\mathrm{NBCR}=\frac{\sum_{i-1}^{n} \frac{B t-C \ell}{(1+i)^{t}}}{\sum_{i-1}^{n} \frac{B t-C t}{(1+i)^{i}}}$

Dimana :

Net $B / C \quad$ : Net manfaat Cost ratio

$\mathrm{Bt} \quad$ : Manfaat pada tahun $\mathrm{t}$

Ct : Biaya proyek pada tahun $\mathrm{t}$

i : : Tingkat suku bunga (required rate of return)

n : : umur ekonomis proyek (Gray, 1993).

3. Internal Rate of Return (IRR)

Kriteria keputusan yang dipilih dalam analisis ini jika IRR lebih besar dari tingkat pengembalian yang diisyaratkan . 
IRR $=\mathrm{i}_{1}+\frac{N P V}{N P V_{1}-N P V_{2}} X\left(i_{2}-i_{1}\right)$

Dimana :

NPV $1 \quad$ : Nilai NPV yang positif

NPV 2 : Nilai NPV yang negatif

i $1 \quad$ : Tingkat bunga pada saat NPV positif

i 2 : tingkat bunga pada saat NPV negatif

Suatu investasi yang diusulkan dinyatakan layak jika IRR lebih besar dari tingkat keuntungan yang dikehendaki. Sebaliknya, jika IRR suatu investasi lebih kecil dari tingkat keuntungan yang dikehendaki maka investasi tersebut dinyatakan tidak layak.

Diskon faktor (DF) digunakan adalah untuk menghitung manfaat sekarang dari suatu nilai yang akan datang pada akhir periode pada tingkat bunga $\frac{1}{(1+1)^{n}}$.

DF merupakan tingkat suku bunga bank yang berlaku dengan kriteria keputusan :

a. jika DF > IRR maka ekowisata mangrove layak diusahakan

b. jika Df < IRR maka ekowisata mangrove tidak layak untuk diusahakan

4. Payback Period

Menurut Gittinger (1986) menyatakan payback period adalah jangka waktu kembalinya keseluruhan jumlah investasi modal yang ditanamkan dihitung mulai dari pemulaan proyek sampai dengan arus nilai neto produksi tambahan, sehingga mencapai jumlah keseluruhan investasi modal yang ditanamkan.

Rumus yang digunakan untuk menghitung PP adalah:

$P P=\frac{1}{A b}$

Keterangan :

$\mathrm{PP}=$ Jumlah waktu (tahun/periode) yang diperlukan untuk mengembalikan modal investasi

$I=$ Jumlah modal investasi

$A b=$ Hasil bersih per tahun/periode atau laba bersih rata-rata per tahun.

5. Analisis Sensitifitas

Parameter yang digunakan untuk mengetahui tingkat sensitivitas ekowisata hutan

mangrove pada penelitian ini adalah berdasarkan tingkat inflasi mata uang yaitu

sebesar 8,38\% dilihat pada data Bank Indonesia (diakses desember 2013) sehingga diasumsikan untuk analisis sensitivitas dengan kenaikan biaya operasional $10 \%$ dan tingkat penurunan manfaat $10 \%$.

\section{HASIL DAN PEMBAHASAN}

\section{Gambaran Umum Lokasi Penelitian}

Desa Sebubus berjarak 4,2 km dari pusat pemerintahan Kecamatan yaitu Liku Desa Nibung, 129 km dari pusat pemerintahan Kabupaten Sambas, $260 \mathrm{~km}$ dari pemerintahan ibu kota provinsi yaitu Kota Pontianak (Bappeda Sambas, 2007). Desa Sebubus merupakan salah satu daerah yang sangat potensial untuk dikembangkan sebagai kawasan ekowisata. Secara umum sumber daya ekowisata yang ada di desa Sebubus maupun di Kecamatan Paloh secara keseluruhan belum dikelola dengan baik padahal sumber daya tersebut dapat dikembangkan untuk mendukung pengembangan kawasan ekowisata di wilayah ini.

Desa Sebubus merupakan salah satu daerah yang sangat potensial untuk dikembangkan sebagai kawasan ekowisata. Secara umum sumber daya ekowisata yang ada di desa Sebubus maupun di Kecamatan Paloh secara keseluruhan belum dikelola dengan baik padahal sumber daya tersebut dapat dikembangkan untuk mendukung pengembangan kawasan ekowisata di wilayah ini. 
Pengembangan ekowisata mutlak harus ditunjang oleh ketersediaan Sumber Daya Manusia (SDM) lokal yang handal dan mampu menciptakan pencitraan yang baik bagi kawasan pengembangan ekowisata tentunya. Pengelolaan ekowisata berujung tombak pada masyarakat lokal, sehingga dalam upayanya masyarakat lokal harus terdidik dan mampu menjaga keberlanjutan program pengembangan ekowisata mangrove di Desa Sebubus terutama dalam mengatasi dampak negatif yang akan muncul akibat kegiatan ekowisata ini. Masyarakat yang tinggal di sekitar hutan mangrove desa Sebubus sebagian besar bermata pencaharian sebagai petani dan nelayan, sehingga hutan mangrove merupakan bagian yang sangat penting bagi masyarakat yang tinggal disekitarnya.

Hal ini sesuai dengan penelitian Kajian Pengembangan Ekowisata Bahari Sebagai Mata Pencaharian Alternatif Bagi Masyarakat di Kabupaten Bintan dari tim PPSPL UMRAH dengan analisis kualitatif terhadap aspek sosial, ekologi, dan potensi dampak negatifmenjelaskan bahwa beberapa kegiatan ekowisata dapat berbenturan dengan norma masyarakat setempat dan terlalu mahal untuk diusahakan sebagai ekowisata berbasis masyarakat namun masih dapat diminimalisir. Sebagai contoh, kegiatan berjemur dan berenang di pantai dengan menggunakan baju terbuka yang umumnya dilakukan sebagian wisatawan mancanegara, sebaiknya jangan dilakukan di sembarangan tempat karena dapat melanggar nilai dan norma budaya setempat. Dampak kegiatan ekowisata seperti ini dapat dihindari asalkan jauh dari pemukiman masyarakat tempatan atau terbatas dalam kondisi areal yang tertutup Hasil penelitian tersebut bisa saja terjadi pada usaha ekowisata mangrove di Sebubus jika tidak diantisipasi sedini mungkin melalui pembinaan kepada masyarakat lokal dan pengelola ekowisata.

Kegiatan pembinaan dapat dilakukan sebagai tahap awal perencanaan dengan memanfaatkan fasilitas yang telah tersedia yaitu Balai Latihan Kerja Kecamatan Paloh yang ada di Desa Sebubus. Penyediaan tenaga handal baik sebagai pengelola, pemilik jasa penginapan ekowisata, pemilik jasa transportasi ekowisata hingga guide lokal dapat dilakukan dengan mendirikan lembaga pendidikan non formal yaitu Pusat Kegiatan Belajar Masyarakat (PKBM) yang dapat dibina langsung oleh Dinas Pendidikan Kabupaten Sambas. Jenis pelatihan yang diberikan disesuaikan dengan jenis produk ekowisata yang akan dikembangkan. Sedangkan perencanaan terhadap pengembangan produk ekowisata disesuaikan pula dengan potensi alam, kapasitas masyarakat, potensi pasar dan ketersediaan sumber-sumber lainnya.

Keberadaan hutan mangrove mempunyai bermacam-macam peranan bagi kehidupan masyarakat desa Sebubus diantaranya mengambil kayu dari hutan mangrove untuk dijadikan kayu bakar, mengambil madu, budidaya siput, budidaya ikan, udang ,kepiting dan mengambil kepah yang biasanya sering dilakukan oleh kelompok ibu-ibu disaat tidak mengerjakan sawah. Karena sebagian besar dari mereka bekerja sebagai petani dan mencari kepah dan siput dilakukan sebagai usaha sampingan saja.

Kawasan pemukiman yang direncanakan untuk dikembangkan terdapat pada kawasan pemukiman nelayan Dusun Jeruju dan Dusun Setingga, sedangkan Dusun Sebuluh dan Dusun Melati merupakan dominansi petani dan wiraswasta serta tidak berada tepat di sekitar pesisir sehingga tidak masuk pada wilayah perencanaan kawasan pemukiman ekowisata. Dusun Jeruju dan Dusun Setingga merupakan kosentrasi utama yang mayoritas penduduknya berprofesi sebagai nelayan di Desa Sebubus, sehingga kesehariannya bergantung pada kehidupan laut dan hutan mangrove. Pertimbangan berikutnya yaitu hanya pada kedua lokasi tersebut terdapat dermaga tradisional nelayan yang dapat dijadikan aksesibilitas menuju obyek kawasan perencanaan ekowisata mangrove.

Pada penelitian ini data masyarakat yang dijadikan responden digunakan untuk memberikan gambaran peluang potensi pengembangan ekowisata hutan mangrove di 
Desa Sebubus. Rata - rata responden berusia produktif sehingga berpotensi berperan sebagai pelaku jasa ekowisata. Ekowisata dipandang dapat memberikan alternatif mata pencaharian dan sumber tambahan pendapatan baru bagi masyarakat tersebut. Hal ini karena disadari bahwa mereka berada di dekat lokasi ekowisata sehingga potensi pasar ada dan dekat,selain itu ekowisata hutan mangrove tidak memerlukan fasilitas penunjang yang mahal.

Sebagian besarmasyarakat desa Sebubus yang dijadikan responden bekerja sebagai nelayan sebanyak $48 \%$ yang di dominasi oleh jenis kelamin laki-laki yang berusia produktif yaitu kisaran usia 20 tahun hingga 55 tahun. Responden yang bekerja sebagai petani sekitar $52 \%$. Sebagian besar rata-rata pendapatan responden (80\%) berkisar antara Rp.500.000-Rp.2.000.000 per bulan yaitu responden yang bekerja sebagai buruh nelayan dan buruh tani. Hanya sebagian kecil dari responden yang berpendapatan lebih dari Rp.2.000.000 per bulan yaitu mereka yang rata-rata tergolong nelayan yang memiliki kapal besar dan alat tangkap lengkap.

\section{Analisis Kelayakan Finansial}

Untuk menganalisis kelayakan usaha ekowisata mangrove di desa Sebubus dari aspek finansial digunakan analisis biaya investasi yaitu biaya-biaya yang dikeluarkan pada tahun pertama usaha atau proyek. Biaya tersebut dikeluarkan untuk memenuhi kebutuhan sarana dan prasarana yang dibutuhkan untuk menjalankan ekowisata hutan mangrove secara keseluruhan. Umur ekonomis dari sarana dan prasarana tersebut adalah 10 tahun, hal ini dilihat dari kondisi bangunan diperkirakan memiliki ketahanan 10 tahun. Biaya investasi tersebut berdasarkan standar harga yang berlaku di daerah setempat sehingga didapat total biaya investasi sebesar Rp. 88.465.178,42 sebagaimana dapat dilhat pada tabel 1.

Tabel 1. Proyeksi Biaya Investasi Ekowisata Mangrove

\begin{tabular}{|c|c|c|c|c|c|c|}
\hline No & Jenis & Jumlah & & Biaya/unit & & Total \\
\hline 1 & $\begin{array}{l}\text { Pembangunan jalan rute } \\
\text { ekowisata }\end{array}$ & 1 & $\mathrm{Rp}$ & $55,320,000.00$ & $\mathrm{Rp}$ & $55,320,000.00$ \\
\hline 2 & Pembangunan pintu gerbang & 1 & $\mathrm{Rp}$ & $5,012,000.00$ & $\mathrm{Rp}$ & $5,012,000.00$ \\
\hline 3 & Pembangunan tempat parkir & 1 & $\mathrm{Rp}$ & $4,975,000.00$ & $\mathrm{Rp}$ & $4,975,000.00$ \\
\hline 4 & Pembuatan papan informasi & 2 & $\mathrm{Rp}$ & $100,000.00$ & $\mathrm{Rp}$ & $200,000.00$ \\
\hline 5 & Pembangunan shelter & 2 & $\mathrm{Rp}$ & $1,000,000.00$ & $\mathrm{Rp}$ & $2,000,000.00$ \\
\hline 6 & Pembangunan pondok wisata & 1 & $\mathrm{Rp}$ & $4,985,000.00$ & $\mathrm{Rp}$ & $4,985,000.00$ \\
\hline 7 & Pembangunan toilet umum & 2 & $\mathrm{Rp}$ & $5,611,589.21$ & $\mathrm{Rp}$ & $11,223,178.42$ \\
\hline 8 & Pembuatan tempat sampah & 5 & $\mathrm{Rp}$ & $150,000.00$ & $\mathrm{Rp}$ & $750,000.00$ \\
\hline 9 & Pembuatan sampan & 4 & $\mathrm{Rp}$ & $1,000,000.00$ & $\mathrm{Rp}$ & $4,000,000.00$ \\
\hline \multicolumn{5}{|c|}{ jumlah } & \multicolumn{2}{|c|}{ Rp $88,465,178.42$} \\
\hline
\end{tabular}

Sumber : Analisis Data Primer, 2013

Selain menganalisis biaya investasi penelitian ini juga menganalisis biaya operasional.Biaya operasional merupakan biaya keseluruhan yang berhubungan dengan kegiatan operasional dari ekowisata hutan mangrove. Biaya tersebut dikeluarkan secara berkala selama ekowisata berjalan yaitusebesar Rp. 77.040.000 per tahun dapat dilihat pada tabel 2. 
Tabel 2. Proyeksi Biaya Operasional

\begin{tabular}{|c|c|c|c|c|c|c|c|c|c|}
\hline \multirow{2}{*}{$\begin{array}{c}\text { No } \\
1\end{array}$} & \multirow{2}{*}{$\begin{array}{l}\text { Komponen } \\
\text { Tenaga kerja }\end{array}$} & \multirow{2}{*}{$\begin{array}{c}\text { Volume } \\
6\end{array}$} & \multirow{2}{*}{$\begin{array}{l}\text { Satuan } \\
\text { orang }\end{array}$} & \multicolumn{2}{|c|}{ Besaran biaya } & \multicolumn{2}{|c|}{ Jumlah/bulan } & \multicolumn{2}{|c|}{ Jumlah /tahun } \\
\hline & & & & $\mathrm{Rp}$ & $900,000.00$ & $\mathrm{Rp}$ & $5,400,000.00$ & $\mathrm{Rp}$ & $64,800,000.00$ \\
\hline 2 & Pembelian bibit mangrove & 1 & periode & $\mathrm{Rp}$ & $500,000.00$ & $\mathrm{Rp}$ & $500,000.00$ & $\mathrm{Rp}$ & $6,000,000.00$ \\
\hline 3 & Perbaikan fasilitas umum & 4 & periode & $\mathrm{Rp}$ & $100,000.00$ & $\mathrm{Rp}$ & $400,000.00$ & $\mathrm{Rp}$ & $4,800,000.00$ \\
\hline 4 & Cetak tiket & 2 & buku & $\mathrm{Rp}$ & $40,000.00$ & $\mathrm{Rp}$ & $80,000.00$ & $\mathrm{Rp}$ & $960,000.00$ \\
\hline 5 & Pembuatan brosur & 20 & lembar & $\mathrm{Rp}$ & $2,000.00$ & $\mathrm{Rp}$ & $40,000.00$ & $\mathrm{Rp}$ & $480,000.00$ \\
\hline \multicolumn{4}{|c|}{ total biaya } & & & $\mathbf{R p}$ & $6,420,000.00$ & $\mathbf{R p}$ & $77,040,000.00$ \\
\hline
\end{tabular}

Sumber : Analisis Data Primer, 2013

Tabel 2 menunjukkan biaya operasional diasumsikan dikeluarkan setiap bulan. Tenaga kerja sebanyak 6 orang dengan pembagian pekerjaan yaitu sebagai penjaga tiket masuk, guide wisatawan, petugas kebersihan, petugas administrasi, dan pengawas lapangan dinilai berdasarkan kisaran upah yang berlaku di desa Sebubus untuk upah buruh tani atau buruh nelayan per hari yaitu Rp.30.000, sehingga apabila diasumsikan mereka bekerja selama sebulan penuh yaitu 30 x Rp. $30.000=$ Rp. 900.000

Tingkat suku bunga bank untuk investasi mengacu pada bunga Bank Rakyat Indonesia untuk Kredit Usaha Rakyat sebesar14 \% per tahun (diakses November 2013) dengan tingkat inflasi sampai periode Desember 2013 yaitu sebesar 8,38 \%.

Manfaat dari kegiatan ekowisata mengrove dihitung berdasarkan rata-rata jumlah dan harga yang ada dilapangan berdasarkan hasil survey dan wawancara dengan masyarakat setempat yang berada di sekitar kawasan hutan mangrove. Manfaat berasal dari penjualan tiket masuk dengan harga Rp. 15.000/ tiket dengan asumsi rata-rata pengunjung tiap minggu 200 orang. Manfaat lainnya yaitu dari retribusi pedagang yang berjualan makanan, minuman, seafood,buah-buahan dan jasa fotografer diasumsikan dengan harga per bulan yaitu Rp. 100.000 untuk tiap-tiap kios yang berjualan. Penyewaan sampan diasumsikan 30 kali dalam seminggu dengan harga Rp.50.000 per satuan, penyewaan pondok wisata untuk pengunjung yang ingin menginap diasumsikan 1 kali dalam seminggu dengan tarif $\mathrm{Rp}$. 450.000 per sekali sewa, dan penyewaan sampan diperkirakan 40 kali dalam sebulan dengan tarif $\mathrm{Rp}$. 50.000 per buah.

Prediksi umur proyek 10 tahun dengan discount factor $14 \%$ maka didapat nilai NPV sebesarRp.4.188.742 artinya proyek ekowisata dengan nilai investasi sebesar Rp. 88.493.178,42 akan menghasilkan nilai bersih sebesar Rp.4.188.742, nilai $\mathrm{Net} B / C 3,5$ artinya setiap Rp.1.000.000 yang dikeluarkan akan menghasilkan Rp.3.500.000 serta IRR $21,68 \%$ berarti kemampuan proyek ekowisata membayar bunga pinjaman yaitu sebesar $21,68 \%$ dengan bunga bank untuk Kredit Usaha Rakyat sebesar 14\% maka nilai IRR tersebut dinilai layak. Berdasarkan nilai kriteria investasi tersebut dapat dilihat bahwa ekowisata mangrove di Desa SebubusKecamatanPaloh Kabupaten Sambaslayak untuk diusahakan NPV bernilai positif dan Net B/C Rasio> 1 (lebih dari besar dari 1) dan nilai IRR $21,68 \%$ sehingga proyek layak untuk dilaksanakan, waktu yang diperlukan untuk pengembalian total investasi yaitu11 bulan.

\section{Analisis Sensitivitas}

Analisis sensitivitaspada penelitian ini ditentukan asumsi sebanyak dua skenario, yaitu kenaikkan biaya operasional sebesar $10 \%$ dan penurunan benefit sebesar $10 \%$ dengan asumsi pertimbangan mengikuti kenaikan atau penurunan tingkat inflasi. Berdasarkan hasil analisis sensitivitas menurunnya nilai NPV, Net B/C Rasio dan IRR yang diperoleh pada saat terjadinya kenaikan biaya operasional dari keadaan normal, menunjukan bahwa proyek ekowisata mangrove sangat peka terhadap kenaikan biaya operasional yang menjadi salah satu komponen yang mempengaruhi manfaat dari 
kegiatan ekowisata mangrove. Berdasarkan hasil perhitungan analisis sensitivitas terhadap kenaikan biaya operasional sebesar $10 \%$ dalam kegiatan ekowisata mangrovedi Desa Sebubus Kecamatan Paloh tidak layak untuk diusahakan dan dikembangkan. Sedangkan hasil perhitungan analisis sensitivitas ekowisata hutan mangrove dengan skenario penurunan benefit sebesar 10\% meghasilkan NPV sebesar Rp.28.315.942, Net B/C Ratio sebesar 0,49, dan IRR sebesar 13,32\%, dari nilai tersebut berarti ekowisata mangrove layak untuk dilaksanakan.

Hasil penelitian ini menunjukkan bahwa ekowisata hutan mangrove memiliki potensi besar untuk dikembangkan sama dengan potensi hutan mangrove yang ada di desa Sebubus Kecamatan Paloh karena dari hasil penelitian Kelayakan Pengembangan Ekowisata Hutan Mangrove di Sebubus Paloh dengan analisis finansial layak untk diusahakan. Hal ini sesuai dengan Penelitian Kajian Pengembangan Ekowisata Bahari Sebagai Mata Pencaharian Alternatif Bagi Masyarakat di Kabupaten Bintan dari tim PPSPL UMRAH dengan analisis potensi ekonomi WTA dan WTP menunjukkan hasil perhitungan menunjukkan bahwa obyek dan kegiatan ekowisata menyelusuri sungai berhutan bakau merupakan obyek ekowisata yang paling layak usaha karena memiliki nilai rasio sangat tinggi yaitu 21.78. Ini berarti bahwa wisatawan bersedia membayar paling tinggi sebesar 21.78 kali dari pada imbalan yang terendah yang diminta oleh masyarakat. Secara keseluruhan, prioritas tertinggi pengembangan suatu ekowisata adalah obyek dan kegiatan ekowisata yang memenuhi semua kriteria kelayakan yang

telah diuraikan sebelumnya yaitu layak ramah lingkungan, ada kesesuaian antara kemampuan masyarakat dan keinginan wisatawan serta layak usaha.

Penelitian tentang Studi Perbandingan Nilai Wisata dan Kayu pada Hutan Produksi di Jawa Barat oleh Karyono dan Subarudi dengan analisis benefit cost ratio belum layak untuk diusahakan apabila di lihat dari nilai benefit cost rasionya yaitu kurang dari satu, hal tersebut di karenakan biaya operasional pada usaha wana wisata lebih besar daripada pendapatan yang diperolehnya.Hasil tersebut sama dengan penelitian ekowisata mangrove di Sebubus pada saat terjadinya kenaikan biaya operasional $10 \%$ menunjukan bahwa proyek ekowisata tersebut tidak layak untuk diusahakan apabila dilihat dari nilai benefit cost rasionya yaitu kurang dari satu tetapipada saat terjadinya penurunan benefit 10\% jika dilihat dari nilai benefit cost rasionya proyek ekowisata mangrove di Sebubus masih layak untuk diusahakan karena menurunnya benefit sebanyak $10 \%$ masih lebih besar daripada biaya operasional proyek ekowisata tersebut.

\section{Penutup}

\section{Kesimpulan}

Ekowisata hutan mangrove di Desa Sebubus Kecamatan Paloh layak untuk dikembangkan, dengan asumsi nilai investasi sebesar Rp.88.465.178 akan menghasilkan nilai bersihsebesar Rp.4.188.742, pada discount factor $14 \%$ selama 10 tahun.Net B/C sebesar 3,5, IRR sebesar 21,68\% dan Payback Period selama 11 bulan. Proyek ekowisata sensitif terhadap kenaikan biaya operasional. Analisis sensitivitas dengan skenario kenaikan biaya operasional $10 \%$ menghasilkan bahwa ekowisata mangrove tidak layak untuk diusahakan karena analisis kelayakan finansialnya benilai negatif. Perhitungan analisis sensitivitas ekowisata hutan mangrove dengan skenario penurunan benefit sebesar 10\% meghasilkan NPV sebesar Rp.28.315.942, Net B/C Ratio sebesar 0,49 , dan IRR sebesar $13,32 \%$, dari nilai tersebut berarti ekowisata mangrove layak untuk dilaksanakan.

\section{Saran}

Potensi hutan mangrove Desa Sebubus perlu dikembangkan lebih lanjut sehingga menjadi produk ekowisata secara nyata sebagai sumber pendapatan baru bagi 
masyarakat yang selama ini mengandalkan hasil tani dan tangkapan ikan di laut saja. Perlunya pengembangan yang terencana untuk segala aspek yang menunjang ekowisata hutan mangrove di Desa Sebubus dan adanya dukungan Pemerintah Daerah untuk mempermudah investor untuk berinvestasi di bidang ekowisata di Sebubus.

\section{DAFTAR PUSTAKA}

Brown, B, 2006. Petunjuk Teknis Rehabilitasi Hidrologi Mangrove. Mangrove Action dan Yayasan Akar Rumput Laut Indonesia. Yogyakarta.

BAPPEDA Sambas, 2007. Rencana Tata Ruang Wilayah Kabupaten Sambas. PEMDA Sambas

Gittinger,1986. Analisa Proyek-Proyek Pertanian. UI Press. Jakarta.

Gray C, 1993. Pengantar Evaluasi Proyek. Gramedia Pustaka Utama. Jakarta

Karyono, Subandi, 2001. Studi Perbandingan Nilai Jasa Wisata dan Kayu pada Hutan Produksi di Jawa Barat. (jurnal)

Tim PPSPL UMRAH, 2010.Kajian Pengembangan Ekowisata Bahari Sebagai Mata Pencaharian Alternatif Bagi Masyarakat di Kabupaten Bintan. 